\title{
Smart Healthcare Devices for Smart Cities: A Review
}

\author{
Adnan Wahid \\ Usman Institute of Technology, Karachi, Pakistan \\ *Corresponding Author, Email: adnan.wahid@aol.com
}

\begin{abstract}
Smart City has become increasingly important worldwide since the last decade. It is the advanced system for communication among people with smart infrastructure ingrained in the smart city. In the smart city, the infrastructure will track and manage all basic facilities, health care, law implementation, water supply, traffic, and transport. Improvement in smart sensor networks, ubiquitous computing, mobile cloud computing, and intellectual services for the communication of information among the sensors, all these facilities built the base for the smart city. The smart health care system will perform an important part in transforming old cities into smart cities. Telecommunication engineering scientists have prepared smarter health services which are improving the standards of living of the society. These health care services significantly develop the quality of health care services in hospitals and also decrease the burden of health care professionals and paramedical staff. This research article presents the applications of a smart health care system which will benefit everyone in the society by providing easy telecommunication access to health care professionals and patients. This system will also track the patient's health online using wearable and implantable devices.
\end{abstract}

Keywords: Smart Health Care, Telecommunication Engineering, Ubiquitous computing, Mobile Cloud Computing, Smart City, Intellectual Services, Wearable, and Implantable Devices

Date Received 24-07-2020

Date Accepted 26-10-2020

Date Published 18-12-2020

\section{INTRODUCTION}

The high standard of life for urban citizens is the assurance provided by the smart city. Innovative ideas and problemsolving methods are required for the progress and execution of the smart city project but still, the innovation period for the perfect meaning of smart city is not over yet but Singh [1] described eight key characteristics for the smart city:

He described the smart city as those cities that compromise at least five qualities out of eight as depicted above. Furthermore, if a city has less than five of these qualities known as an eco-friendly city.

Several years back the knowledge of big data gained popularity and recognized as a new research area. Data exist in every computer in all generations this mean big data is not a new concept. Due to the advancement in technology in every field, and the utilization of these technologies has created a stack of data. Big data is about the usage of enormous data proficiently for estimation and recommendations on it.

Many people in society are prone to diseases especially the young population is vulnerable to chronic syndromes, hypersensitivity, diabetes, lung diseases, loss of memory, mental or physical disability, etc. are the basic issues in society. Lack of awareness of healthy activities like sports, exercise, etc. is the major challenge in smart cities for a healthy life. This paper will discuss smart healthcare devices

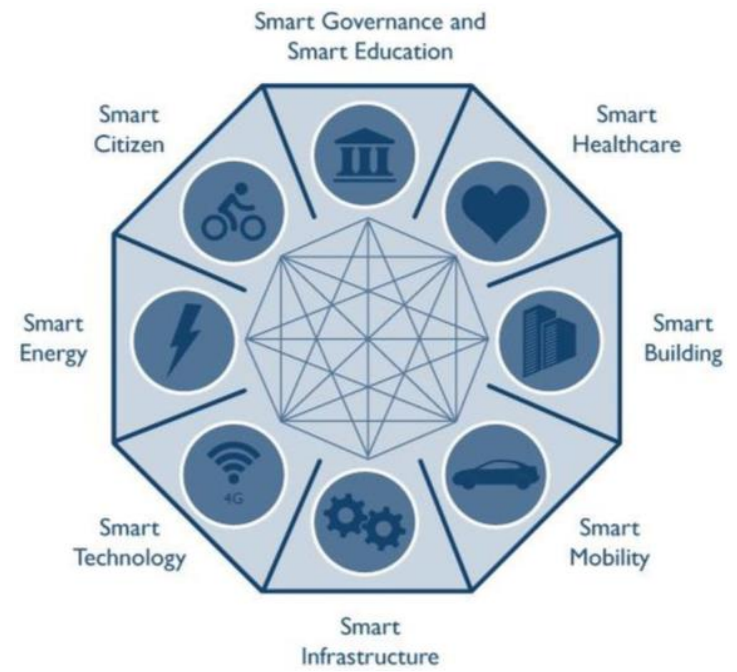

Fig 1. The Smart City Concept [1]

and their applications that can be provided in smart cities.

Real-time sensors and communication infrastructure is the prime requirement for the smart city. Real-time sensors are required to gather environment data. Gathered data become huge over a passage of time, at this stage; big data plays an important role when smart devices and sensors generate data. Collected data is used for making real-time decisions. The smart city is the need of the current era for better living norms of citizens. Many renowned companies are investing in research and inventing to build the infrastructure of the smart city project. As stated by the World Health Organization's global health report, $54 \%$ of the population lives in the city which is estimated to grow by $70 \%$ by 2050 [2]. Numbers and 
figures reveal the need for the deployment of infrastructure and efficient management for the population.

\section{A COMPARISON AMONG E-HEALTH, M-HEALTH, AND S- HEALTH}

For the past twenty years, information technology has significantly used in the health domain. It introduced the notion of electronic health (e-Health) system. Improved patient documentation process by keeping track of patient health history and procedures performed on patients. Conventionally health care practitioners keep patient records and history on paper. Further improvement in the technology developed cellular phones which introduced us to the mobile health (m-Health) system.

$\mathrm{m}$-Health is a common word used for cellular phone technology or any other wireless technology in the medical domain. Applications of $\mathrm{m}$-health involve the use of mobile technology to train consumers regarding precautionary healthcare services. In addition to this, m-health is also used for treatment support, chronic and acute disease management, epidemic outbreak, and treatment support and disease investigation. Nowadays, m-health is becoming the most common choice is the unprivileged area where the use of a mobile phone is very common.

With the advancement, the field of Information Technology, the concept of smart health (s-health) system has become popular. It is the combined form of $m$-health and intelligent sensors. It uses the latest information technology, such as artificial intelligence, cloud computing, big data; wearable devices, and mobile internet, Internet of things (IoT). With the integration of m-health with intelligent sensors, it allows to access the information dynamically, distribute information among people and medical institutions. s-health can encourage collaboration among the stack holder of the healthcare domain. It ensures the services to the members, helps the members to make informed decisions, and provides the balance distribution of allocation. In conclusion, the s-health care system is the advanced level of information construction in the health care area [3].

\section{LITERATURE SURVEY OF SMART HEALTHCARE SYSTEM}

A healthy lifestyle plays an important role, a demanding and stressful life with unhealthy intake and lack of exercise or sports activity, and other factors have made people's life susceptible to diseases. This has become a challenge to the health sector area due to the increased demand for health practitioners. An alternative to this problem is to adopt the modern healthcare application which can track and maintain the fitness, inform and alert about the precautionary measures, epidemics, etc. The wearable and implantable devices can be utilized for healthcare monitoring and making a proper decision on predictions. Many smart cities have adopted these healthcare devices.

\section{A.Smart Homecare Services}

In many regions in the world, aging is the prime concern. This increases the requirement of health care services. To fulfill the requirement of healthcare, experts provided the many innovative ideas like:
- The routine checkup of older people by healthcare practitioners or staff by visiting their homes. Complete history and medical record of patients is maintained including digital images of the medical reports, patients' physical and mental health condition, etc. In the future, this data can be used to understand patient history or even it can be accessed by the health staff using a smartphone [4].

- E-homecare services are the extension in-home care services which include scheduled vaccinations, daily exercise, balanced diet management, and health monitoring [5].

- Home monitoring technology is used under the floor to help an old and weak person living independently alone at home. The dense array of piezo elements are used to implement the sensor floor, which can inform us about the movement of a person [6].

- The prime role of assistive technology for aged people with disabilities is to provide support and care. For the monitoring of these people, a large array of pressure sensor sensitive tile is implemented in floors [7].

- Heart patients need intense care and support especially in a situation like a fall, intrusion, and other danger. Implantable devices that can monitor the dynamics of blood flow like hemodynamic monitors significantly reduce the heart failure hospitalization rate. [8].

The popularity of smart homes becomes significant in 2000 . Smart homes are available at reasonable rates including home technologies, home networks, and other smart appliances. Recently smart homes are equipped with advanced sensors, cognitive technologies, ubiquitous computing, and IoT.

B. Portable Healthcare Devices Associated with Smart Phone

Many regions in the world, portable medical devices are used with smartphones to cut the medical equipment is cost.

- Many portable ultrasound technologies like "Mobisante" [9] and "Butterfly iQ" [10] are available that works with a smartphone. Health practitioners use these technologies in unprivileged areas for heart patients, kidney patients, and pregnant women. The captured images transmitted to the hospital with the help of a smartphone.

- A mental healthcare system like "ROCHAS" [11] is for elderly, isolated, and depressed people.

- "Smart Temporal Thermometer" measures the body temperature from the temporal artery, as the core body blood circulates from the temporal artery; it is considered the best place to measure temperature changes. [12], [13].

\section{Smart Wearable Devices}

Smart wearable devices indicated many benefits for an individual against many serious health conditions like diabetes, joint pain problems, cancer, heart diseases, high blood pressure, etc.

- "LifeLine" is a health monitoring bracelet that keeps track of a person's heartbeat, the glucose level in the blood, the temperature of the human body, and share the user information to their mobile or personal computer [14].

- "Lumo Run" and "Lumo Lift", is a wearable sensor that monitors and analyzes the human biomechanics. It offers 
real-time audio coaching and pre and post exercise recommendations based on data [15].

- "K'Watch Glucose" is a continuous glucose monitor wearable device that tracks blood glucose levels and provides alerts when the blood sugar level is high or too low [16].

- "CardioMobile", a distant observing system for a heart patient. The heart patient can take part in the supervised rehabilitation exercise if the patient cannot attend the hospital-based exercise program [17].

\section{D.Smart Textiles and Footwear}

Smart garment plays an important role to monitor one's health state factors like a pulse rate, blood oxygen, febricity, breathing rate, deportment, and some exterior aspects like air quality, temperature, humidity, etc. Furthermore, it may not change the appearance of clothing and thus enables the wearer to privately use the technology.

- "ProeTEX" project is aimed to ensure the safety and for the better efficiency of rescuer, smart wearable cloths with communication system are introduced to monitor the body parameters, movement type, location and their environment during rescue operations [18], [19].

- "BBA bootee" provides information on the infant's activity and oxygen saturation level in blood. With the help of this smart device, chronic lung disease, malformation syndromes, major prematurity can be avoided [20].

- "GaitShoe" provides information on a person's manner of walking. Its application is to differentiate between healthy gait and Parkinsonian gait on an individual according to its output pattern [21].

- "e-Shoe" provides the information of gait [22].

- "Arduino Lilypad" shoes are primarily for visually impaired people to avoid obstacles to reach their destination [23].

\section{E. Smart Healthcare Mobile Applications}

The in-built sensors and ever-growing arithmetic abilities of smartphones have shifted the trend towards mobile-based health diagnostic systems.

- "MobSpiro" is the smartphone-based software for identifying chronic obstructive pulmonary disease (COPD). COPD is a respiratory syndrome in which patients suffer from difficulty in breathing. MobiSpiro uses a mobile microphone to analyze the patient's lung airflow. The mobile proximity sensor is used to optimize the patient and microphone distance [24].

- Pulmonary Rehabilitation treatment is helpful for chronic obstructive pulmonary disease patients. In this treatment, the heart rate is measured during the workout session using a wireless pulse oximeter module [25].

- Human facial expression changes with different health states. With this system, the health practitioner can continuously monitor the facial expression remotely and can take action according to health conditions [26].

- The eCAALYX smartphone application aims to build a remote monitoring system for mature people with various chronic diseases [27].

\section{F. Smart Implantable Devices}

Smart implantable devices placed in a body during a medical procedure to monitor health and study body organ's normal and abnormal functioning.

- The "SmartPill" system consists of an ingestible capsule, wireless transmitter with sensors, and a "MotiliGI" display software. The display software captures data at regular intervals for graphical display [28].

- In the hemodynamic monitoring system, the implantable CardioMEMS sensor provides vital information to a health practitioner to enhance the timings of the left ventricular assist device (LVAD) and helps to prevent cardiac arrest [29].

\section{SUMMARY}

In this review, the modern developments in smart healthcare systems are highlighted. Considerable progress has been made in smart cities, smart healthcare systems, and conventional healthcare methods. The recent systems include routine checkups of older people, scheduled vaccination, diet monitoring, and home monitoring technology for disabled persons. Many portable devices have introduced for remote areas where health facilities are limited. Smart wearable devices including bracelets, watches, and wearable sensors are used to keep a record of glucose level, body temperature, blood pressure, pulse rate, ECG, etc. Smart fabrics are used to ensure the safety of rescuers and to prevent serious illnesses in infants at their early stages. Footwear is beneficial to obstruct the human gait problem and to provide aid to blind people. Smart implantable devices are helpful to monitor abnormality in internal human organs. To sum up, maximum smart devices and applications are showcased in this review paper.

\section{REFERENCES}

[1] S. Singh, "Smart Cities -- A \$1.5 Trillion Market Opportunity," Forbes. https://www.forbes.com/sites/sarwantsingh/2014/06/19/smartcities-a-1-5-trillion-market-opportunity/ (accessed Apr. 25, 2020).

[2] WHO Global Observatory for eHealth and World Health Organization, MHealth: new horizons for health through mobile technologies. Geneva: World Health Organization, 2011.

[3] S. Tian, W. Yang, J. M. L. Grange, P. Wang, W. Huang, and Z. Ye, "Smart healthcare: making medical care more intelligent," Glob. Health J., vol. 3, no. 3, pp. 62-65, Sep. 2019, doi: 10.1016/j.glohj.2019.07.001.

[4] C. L. Ventola, "Mobile Devices and Apps for Health Care Professionals: Uses and Benefits," Pharm. Ther., vol. 39, no. 5, pp. 356-364, May 2014.

[5] J. Tan, "E-Health Care Information Systems: An Introduction for Students and Professionals | Wiley," Wiley.com. https://www.wiley.com/enus/E+Health+Care+Information+Systems \%3A+An+Introducti on+for+Students+and+Professionals-p-9780787977412 (accessed May 03, 2020).

[6] P. Leusmann, C. Mollering, L. Klack, K. Kasugai, M. Ziefle, and B. Rumpe, "Your Floor Knows Where You Are: 
Sensing and Acquisition of Movement Data," in 2011 IEEE 12th International Conference on Mobile Data Management, Lulea, Sweden, Jun. 2011, pp. 61-66, doi: 10.1109/MDM.2011.29.

[7] R. Andrich, N.-E. Mathiassen, E.-J. Hoogerwerf, and G. J. Gelderblom, "Service delivery systems for assistive technology in Europe: An AAATE/EASTIN position paper," Technol. Disabil., vol. 25, no. 3, pp. 127-146, Aug. 2013, doi: 10.3233/TAD-130381.

[8] W. T. Abraham and L. Perl, "Implantable Hemodynamic Monitoring for Heart Failure Patients," J. Am. Coll. Cardiol., vol. 70, no. 3, pp. 389-398, Jul. 2017, doi: 10.1016/j.jacc.2017.05.052.

[9] "Portable Ultrasound Machine | Mobisante." http://www.mobisante.com/ (accessed May 05, 2020).

[10] "Butterfly iQ - Ultrasound, ultra-simplified." https://www.butterflynetwork.com/ (accessed May 05, 2020).

[11] M. Chen, Y. Ma, S. Ullah, W. Cai, and E. Song, "ROCHAS: robotics and cloud-assisted healthcare system for empty nester," in Proceedings of the 8th International Conference on Body Area Networks, Boston, Massachusetts, Sep. 2013, pp. 217-220, doi: 10.4108/icst.bodynets.2013.253922.

[12] "Smart Temporal Thermometer - Thermo | Withings." https://www.withings.com/nl/en/thermo (accessed Jun. 21, 2020).

[13] G. J. Paik et al., "Accuracy of Temporal Artery Thermometry as an Indicator of Core Body Temperature in Patients Receiving General Anesthesia," J. Perianesth. Nurs., vol. 34, no. 2, pp. 330-337, Apr. 2019, doi: 10.1016/j.jopan.2018.05.001.

[14] "LifeLine." https://lifelineblog.tumblr.com/?og=1 (accessed Jun. 04, 2020).

[15] "Lumo BodyTech - Technology for a Healthy Lifestyle." https://www.lumobodytech.com/ (accessed Jun. 04, 2020).

[16] "K'Watch Glucose," PKVitality. https://www.pkvitality.com/ktrack-glucose/ (accessed Jun. 04, 2020).

[17] "CardioMobile: A remote monitoring system for cardiac rehabilitation," Galileo Masters. /winner/cardiomobileremote-monitoring-system-cardiac-rehabilitation/ (accessed Jun. 04, 2020).

[18] "PROeTEX Home." http://www.proetex.org/ (accessed Jun. 08, 2020).

[19] D. Curone et al., "Smart Garments for Emergency Operators: The ProeTEX Project," IEEE Trans. Inf. Technol. Biomed., vol. 14, no. 3, pp. 694-701, May 2010, doi: 10.1109/TITB.2010.2045003.

[20] Y. Rimet et al., "Surveillance of infants at risk of apparent life threatening events (ALTE) with the BBA bootee: a wearable multiparameter monitor," in 2007 29th Annиal International Conference of the IEEE Engineering in Medicine and Biology Society, Lyon, France, Aug. 2007, pp. 4997-5000, doi: 10.1109/IEMBS.2007.4353462.

[21] S. Bamberg, A. Y. Benbasat, D. M. Scarborough, D. E. Krebs, and J. A. Paradiso, "Gait Analysis Using a ShoeIntegrated Wireless Sensor System," IEEE Trans. Inf. Technol. Biomed., vol. 12, no. 4, pp. 413-423, Jul. 2008, doi: 10.1109/TITB.2007.899493.
[22] H. Jagos and J. Oberzaucher, "Development of a Wearable Measurement System to Identify Characteristics in Human Gait - eSHOE -," in Computers Helping People with Special Needs, Berlin, Heidelberg, 2008, pp. 1301-1304, doi: 10.1007/978-3-540-70540-6_194.

[23] S. Jayashree, R. Kruthika, and R. R. K. Shankar, "ARDUINO LILYPAD SHOES FOR VISUALLY," vol. 6, no. 10, p. 5, 2015.

[24] F. Zubaydi, A. Sagahyroon, F. Aloul, and H. Mir, "MobSpiro: Mobile based spirometry for detecting COPD," in 2017 IEEE 7th Annual Computing and Communication Workshop and Conference (CCWC), Las Vegas, NV, USA, Jan. 2017, pp. 1-4, doi: 10.1109/CCWC.2017.7868345.

[25] J. Tang, A. Mandrusiak, and T. Russell, "The Feasibility and Validity of a Remote Pulse Oximetry System for Pulmonary Rehabilitation: A Pilot Study," Int. J. Telemed. Appl., vol. 2012, 2012, doi: 10.1155/2012/798791.

[26] G. Muhammad, M. Alsulaiman, S. U. Amin, A. Ghoneim, and M. F. Alhamid, "A Facial-Expression Monitoring System for Improved Healthcare in Smart Cities," IEEE Access, vol. 5, pp. 10871-10881, 2017, doi: 10.1109/ACCESS.2017.2712788.

[27] M. Boulos, S. Wheeler, C. Tavares, and R. Jones, "How smartphones are changing the face of mobile and participatory healthcare: an overview, with example from eCAALYX," Biomed. Eng. OnLine, vol. 10, no. 1, p. 24, 2011, doi: 10.1186/1475-925X-10-24.

[28] S. Maqbool, H. P. Parkman, and F. K. Friedenberg, "Wireless capsule motility: comparison of the SmartPill GI monitoring system with scintigraphy for measuring whole gut transit," Dig. Dis. Sci., vol. 54, no. 10, pp. 2167-2174, Oct. 2009, doi: 10.1007/s10620-009-0899-9.

[29] D. S. Feldman et al., "The Utility of a Wireless Implantable Hemodynamic Monitoring System in Patients Requiring Mechanical Circulatory Support," ASAIO J. Am. Soc. Artif. Intern. Organs 1992, vol. 64, no. 3, pp. 301-308, Jun. 2018, doi: 10.1097/MAT.0000000000000670.

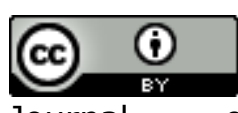

Journal of Applied and Emerging Sciences by BUITEMS is licensed under a Creative Commons Attribution 4.0 International License. 